\title{
Rotulagem de alimentos que contém Organismos Geneticamente Modificados: políticas internacionais e Legislação no Brasil
}

\author{
Labeling of food containing Genetically M odified Organisms: \\ international policies and Brazilian legislation
}

Thadeu Estevam M oreira M aramaldo Costa ${ }^{1}$

Victor Augustus $M$ arin ${ }^{2}$

${ }^{1}$ Laboratório de

FarmacologiaAplicada,

Instituto deTecnologiaem

Fármacos, Farmanguinhos/

Fiocruz. RuaSizenando

Nabuco 100, Manguinhos

21041250 Rio deJaneiro RJ.

thadeucosta@far.fiocruz.br

${ }^{2} \mathrm{Nú}$ cleo del novação

Tecnológica do INCQS/

Abstract The increase in surface area planted with genetically modified crops, with the subsequent transfer of such crops into the general environment for commercial trade, has raised questions about the safety of these products. The introduction of the Cartagena Protocol on Biosafety hasled to the need to produce information and ensure training in this area for the implementation of policies on biosafety and for decision-making on the part of governments at the national, regional and international level. This article presents two main standpoints regarding the labeling of GM products (one adopted by the United States and the other by the European Union), as well as the position adopted by Brazil and its current legislation on labeling and commercial release of genetically modified (GM) products. Key words Genetically modified organisms, International Policies, Brazilian legislation
Resumo 0 crescimento da área desuperfícieplantada com as culturas geneticamente modificadas, com a consequente liberação dessas lavouras para o ambiente e para a comercialização, levantou questionamentos sobre a segurança destes produtos. A entrada em vigor do Protocolo de Cartagena sobre Biossegurança , fez com que houvesse a necessi dade de aquisição de informações e capaci tação nesta área para a implementação de políticas de biossegurança e para tomadas de decisões por partes dos governos em níveis nacionais, regionais e internacionais. 0 presente artigo apresenta as duas principais vertentes políticas sobre rotulagem de produtos geneticamente modificados (uma adotada pelos Estados U nidos da A mérica e outra pela União Europeia), assim como a posição adotada pelo Brasil e sua atual legislação acerca de rotulagem e liberação comercial de produtos geneticamente modificados (GM).

Palavras-chaves Organismosgeneticamentemodificados, PolíticasInternacionais, Legislação brasileira

Fiocruz (NIT-INCQS). 
Introdução

Nos últimos anos, houve um crescimento dramático e gradual na superfície de área plantada com culturas transgênicas, sendo os Estados Unidos os maiores produtores e consumidores destas com mais de dois terços da produção mundial ${ }^{1}$.

Embora as primeiras culturas geneticamente modificadas comercializadas tenham sido plantadas em 1994 (tomates), 1996 foi o primeiro ano em que uma área significativa (1,66 milhões de hectares) de culturas foi plantada contendo características geneticamente modificadas. Desde então, tem havido um aumento dramático em plantações eem 2005/06, a área mundial plantada atingiu quase 87,2 milhões dehectares. Isto éigual a cinco vezes a superfície agrícola total ou dezenovevezeso total deárea cultivável do Reino Unido².

Enquanto 22 países plantaram lavouras biotecnológicas comercializadas em 2006, 29 outros países, totalizando 51, concederam, desde 1996, aprovações regulatórias para lavouras biotecnológicas serem importadas, utilizadas em alimentose forragem, eliberadas no meio ambiente. Um total de 539 aprovações foi concedido para 107 eventos de 21 tipos de cultura. Sendo assim, os produtos biotecnológicos podem ser importados, utilizados em alimentos e forragens e liberados no meio ambiente em 29 países, inclusive nos maiores países importadores de alimentos como o Japão, que não planta lavouras biotecnológicas. Dos 51 países que concederam aprovações para o plantio delavouras biotecnológicas, osEUA encabeçam a lista, seguidos pelo Japão, Canadá, Coreia do Sul, Austrália, Filipinas, M éxico, Nova Zelândia, União Europeia, e China. 0 milho tem a maioria dos eventos aprovados (35), seguido pelo al godão (19), a canola (14) e a soja (7)3.

A liberação delavouras geneticamente modificadas (GM) no ambiente e no mercado levantou diversas questões a respeito da segurança desses produtos. A complexidade das discussões é decorrente de dois fatores principais: por um lado, a base de conhecimentos científicos sobre as implicações e os impactos da liberação em larga escala de plantas transgênicas para o cultivo comercial é ainda insuficiente; por outro lado, a questão das plantas transgênicas enseja uma abordagem inter e multidisciplinar, uma vez que os impactos são diferenciados, os conflitos de interesses são múltiplos e o diálogo apenas recentemente vem se tornando público ${ }^{4,5}$.

A grande questão que vem sendo levantada é o quão seguras são essas tecnologias e se estão de acordo com o Guia Internacional para Segurança em Biotecnologia (IGSB), aceito pelo Programa Ambiental das Nações Unidas. Atualmente os argumentos dos partidários do princípio da precaução obrigam os governos de muitos países na União Europeia, Ásia e África a modificar suas políticas e desistir da produção de variedades $\mathrm{GM}^{6}$.

Embora a produção e venda de produtos al imentares geneticamente modificados (GM) tenham começado há cerca de uma década, ainda há incertezas e controvérsias sobre como estes devem ser regulamentados ${ }^{7}$.

Políticas Internacionais de Rotulagem deProdutos que Contém Organismos GeneticamenteM odificados

Os sistemas de segurança alimentar, que incluem instituições, políticas, leis e diretrizes para avaliações, evoluem continuamente ao longo do tempo. A evolução dos sistemas de segurança dos alimentos em cada jurisdição é afetada tanto pela ciência quanto pela sociedade: os avanços científicos aumentam a nossa compreensão das consequências dos alimentos sobre saúde e levam à adoção de novas tecnologias de produção de alimentos agrícolas, alguns dos quais requerem regulamentação. A alteração dos valores sociais pode levar a mudanças na política de defesa dos consumidores e nas regulamentações. Estas, por sua vez, podem afetar tanto a inovação quanto a percepção do risco. A Organização para a Cooperação Econômica eD esenvolvimento (OECD) compilou descrições dos sistemas nacionais de segurança alimentar dos seus vinte e nove Estados membros; essas descrições também endereçam especificamente as abordagens nacionais para a regulação e a avaliação de alimentos produzidos a partir de culturas geneticamente modificadas?.

Durante os últimos dez anos, mais de 40 países adotaram políticas de rotulagem para alimentos geneticamente modificados, mas as características das regulamentações e seu grau de execução variam enormemente. Embora a grande maioria dos países pertencentes à OECD tenham implementado algum tipo de política de rotulagem, poucos países em desenvolvimento introduziram leis para rotulagem, ou mesmo as implementaram?.

Após a entrada em vigor do Protocolo de Cartagena sobre Biossegurança em 11 de setembro de 2003, houve uma necessidade urgente de aquisição deinformações e capacitação nesta área 
para a implementação de políticas de biossegurança e para tomadas de decisões por partes dos governos em níveis nacionais, regionais e internacionais ${ }^{10}$.

A Convenção sobre Diversidade Biológica e o Protocolo de Cartagena

Em 1992 uma Conferência das N ações Unidas sobreM eio AmbienteeD Desenvolvimento foi realizada no Rio de Janeiro. Nesta conferência, 172 governos acordaram sobre vários documentos, entre os quais estavam a Agenda 21 e a Conven ção sobre a Diversidade Biológica. Os objetivos da Convenção são a conservação da diversidade biológica, a utilização sustentável dos seus componentes ea partilhajusta e equitativa dos ben efícios decorrentes da utilização dos recursos genéticos ${ }^{10}$.

o Protocolo de Cartagena sobre Biossegurança é o primeiro acordo firmado no âmbito da Convenção sobre Diversidade Biológica (CBD). Visa assegurar um nível adequado de proteção no campo da transferência, da manipulação e do uso seguro dos organismos vivos modificados (OVM s) resultantes da biotecnologia moderna que possam ter efeitos adversos na conservação e no uso sustentável da diversidade biológica, levando em conta os riscos para a saúde humana, decorrentes do movimento transfronteiriço ${ }^{11}$.

O Protocolo foi adotado em 2000 e entrou em vigor em setembro de 2003. É o primeiro instrumento juridicamente vinculativo global incidindo sobre OVM. O protocolo estabelece que haja um prévio acordo que exige, antes da primeira introdução intencional no ambiente de uma parte importadora, a notificação do partido de exportação que contenham certas informações, o reconhecimento da sua recepção e o consentimento escrito da parte de importação. Critérios são fornecidos para a tomada de decisões sobre a importação, em especial, que deve ser feita de acordo com uma avaliação de risco ${ }^{10}$.

A adoção do Protocolo pelos Países-Partes da Convenção constitui-se em um importante passo para a criação de um marco normativo internacional que leva em consideração as necessidades de proteção do meio ambiente e da saúde humana e da promoção do comércio internacional. Da mesma forma, cria uma instância internacional para discutir os procedimentos que deverão nortear a introdução de organismos vivos modificados em seus territórios. N este contexto, cabe salientar que o Protocolo incorpora o
Princípio da Precaução (onde existam ameaças de riscos sérios ou irreversíveis, a falta de completa certeza científica não deve ser utilizada como razão para 0 adiamento de medidas eficazes em termos de custos para evitar a degradação ambiental), um dos pilares mais importantes desse instrumento eque deve nortear as ações políticas e administrativas dos governos ${ }^{11}$.

o Protocolo fornece guias de avaliações de risco e medidas para seu gerenciamento. Essas avaliações devem ser realizadas de maneira que seja cientificamente correta etransparente, ecaso a caso. Segundo o protocolo, a falta de conhecimentos científicos ou de consenso científico não deve necessariamente ser interpretada como indicativo de um determinado nível de risco, uma ausência de risco ou um risco aceitável ${ }^{11}$.

Atualmente, o Protocolo de Cartagena conta com 143 países-partes (com 103 assinaturas), entreeles o Brasil, quesereúnem periodicamente (Conference of the Parties - COP; M eeting of the Parties - MOP) para discutir e decidir sobremedidas para minimizar a probabilidade de movimentos transfronteiriçosnão intencionais, reduzindo desta forma a possibilidade de ocorrência de efeitos adversos sobre 0 ambiente que possam afetar a conservação e o uso sustentável da diversidade biológica12.

A última reunião da Conferência das Partes do Protocolo de Cartagena sobre Biossegurança (COP8/ M OP3) foi realizada nos dias 13 a 17 de $\mathrm{M}$ arço de 2006, em Curitiba, Brasil. De acordo com o programa de trabal ho em médio prazo da COP-MOP, a reunião aprovou decisões como: requisitos detalhados para documentos que acompanham organismos vivos modificados destinados a serem utilizados diretamente na alimentação humana ou animal, ou para processamento; manipulação, transporte, embalagem e identificação; a necessidade de desenvolvimento de normas no que diz respeito à identificação, manipulação, embalagem e transporte para os movimentos transfrontei riços de OVM ; avaliação de riscos e de gestão de risco; a necessidade de estabelecer órgãos subsidiários no âmbito do protocolo; outras questões necessárias para a implementação efetiva do Protocolo (direitos e/ ou obrigações das partes de trânsito); monitorização e comunicação no âmbito do protocolo ${ }^{12}$.

Internamente, a adesão do Brasil ao Protocolo reveste-se de grande importância em razão da sua condição de país megadiverso e, também, de exportador de alimentos. É a primeira vez que a comunidade internacional aprova um acordo queimpõe regras ao comércio de produtos trans- 
gênicos. Trata-se, portanto, de um instrumento dedireito internacional quetem por objetivo proteger os direitos humanos fundamentais, tais como a saúdehumana, a biodiversidade e o equilíbrio ecológico do meio ambiente, sem os quais ficam prejudicados os direitos à dignidade, à qualidade de vida e à própria vida, direitos estes garantidos pela Constituição Federal de 1988 e consagrados pela Declaração Universal dos Direitos Humanos da Organização das N ações Unidas, de $1948^{11}$.

\section{Abordagens I nternacionais}

para a Rotulagem de Produtos GM

Internacionalmente, a Comissão do Codex Alimentarius, um órgão de padronização das normas internacionais para alimentos, tem um comitê sobre rotulagem de alimentos. Desde 1990, o Codex tem procurado desenvolver orientações para rotular alimentos oriundos da biotecnologia ${ }^{13}$.

Nos últimos anos, um número crescente de países adotou políticas de rotulagem de alimentos geneticamente modificados. As primeiras políticas de rotulagem foram introduzidas pela União Europeia (UE) em 1997. Desde então, muitos outros países, incluindo todos os países desenvolvidos, têm adotado algum tipo de política para rotulagem dos alimentos geneticamente modificados. No entanto, estas políticas de rotulagem diferem muito em sua natureza, seu alcance, sua cobertura, suas exceções e seu grau de execução. Consequentemente, os efeitos observados dessas políticas sobre a escol ha dos consumidores, a informação para os consumidores, o comércio dos alimentos e o comércio internacional também variam significativamente ${ }^{9}$.

Existe uma enorme lacuna entre as abordagens adotadas nos diferentes países para a rotulagem dos alimentos geneticamente modificados. Por exemplo, a UE tem orientações muito rigorosas para a rotulagem de OGM. Por outro lado, estão os Estados Unidos, a Argentina e o Canadá, cujos governos não acreditam na rotulagem obrigatória. Japão, Coréia do Sul, China e outros países estão em um meio termo entre a UE e os Estados Unidos sobre este tema. A razão apontada para o governo dos Estados Unidos não apoiarem a obrigatoriedade derotulagem dos alimentos geneticamente modificados é que a Food and D rug Administration (FDA) considera que não há provas científicas de que alimentos geneticamentemodificados são nutricionalmentediferentes dos alimentos convencionais não-GM ${ }^{14}$.
As diretrizes para rotulagem voluntária ditam regras que definem quais alimentos podem ser chamados de GM e não-GM, e deixam as empresas de alimentos decidirem se querem utilizar essas informações em seus produtos. Em contrapartida, os países cuja rotulagem é obrigatória requerem que as empresas de alimentos (transformadores, retalhistas e, por vezes, os produtores) detalhem se o produto/ingrediente alvo contém ou é obtido a partir de engenharia genética. Alguns países, com rotulagem obrigatória para ingredientes GM também têm diretrizes voluntárias para a rotulagem de alimentos não-GM (por exemplo, Japão eU nião Europeia). Este sistema misto obrigatório/facultativo está em vigor nos países com rotulagem obrigatória nos quais os consumidores estão dispostos a pagar um valor maior para evitar completamente ingredientes geneticamente modificados, mesmo que em nível residual ${ }^{9}$.

Uma das grandes diferenças entre os regulamentos dos países que adotam a rotulagem obrigatória depende se é visada a presença de O GM no produto final (como a Austrália, Nova Zelândia eJ apão) ou se visa a utilização da tecnologia do DNA recombinante como parte do processo de produção (como a UE, Brasil e China) ${ }^{9}$.

0 Quadro 1 demonstra as abordagens internacionais de rotulagem de acordo com seu grau derigidez.

\section{Rotulagem de Produtos GM na União Europeia}

A partir demeados dos anos noventa, principalmente, em decorrência das crises alimentares provocadas pelo surgimento da doença da vaca louca (Encefalopatia Espongiforme Bovina) e da contaminação inicial de frangos na Bélgica pela presença de dioxinas em rações, que se estendeu por toda a Europa, a segurança sanitária dos alimentos adquiriu destaque na segurança alimentar. Isso, porque essas novas crises alteraram radicalmente a percepção dos consumidores sobre a qualidade dos alimentos e tornando-os mais exigentes sobre a ação do Estado para vigilância e controle da qualidade sanitária dos al imentos. Essa condição foi reforçada pelo surgimento da gripedo frango (Influenza aviária), originária nos países asiáticos e que começou a se proliferar nos EUA e Norte da Europa, provocando crise de origem sanitária no setor ${ }^{15}$.

Os produtos alimentares que contém OGM já estão disponíveis há algum tempo, embora muitos consumidores não tenham consciência 
Quadro 1. Características dos sistemas nacionais de rotulagem nos principais países de acordo com o grau de rigidez de suas regulamentações.

\begin{tabular}{|c|c|c|c|c|}
\hline País & $\begin{array}{c}\text { Tipo de } \\
\text { Rotulagem }^{a}\end{array}$ & $\begin{array}{l}\text { Produto/ } \\
\text { Processo }\end{array}$ & Cobertura & $\begin{array}{l}\text { Limites de } \\
\text { detecção }\end{array}$ \\
\hline União Europeia & $\begin{array}{l}\text { obrigatória e } \\
\text { orientações para } \\
\text { rotulagem } \\
\text { voluntáriah }^{h}\end{array}$ & processo & $\begin{array}{l}\text { Alimentos, rações, aditivos, } \\
\text { aromatizantes, produtos derivados de } \\
\text { GM, restaurantes }\end{array}$ & $0,9 \%$ \\
\hline Brasil b & obrigatória & processo & $\begin{array}{l}\text { Alimentos, rações, produtos derivados de } \\
\text { GM, carne e produtos animais }\end{array}$ & $1 \%$ \\
\hline China & obrigatória & processo & $\begin{array}{l}\text { Lista, produtos derivados de GM, } \\
\text { restaurantes }\end{array}$ & $0 \%$ \\
\hline $\begin{array}{l}\text { Austrália/Nova } \\
\text { Zelândia }\end{array}$ & $\begin{array}{l}\text { obrigatóriae } \\
\text { voluntáriah }\end{array}$ & produto & Todos os produtos baseados em conteúdo & $1 \%$ \\
\hline Japão & $\begin{array}{l}\text { obrigatóriae } \\
\text { voluntáriah }\end{array}$ & produto & & $5 \%{ }^{f}$ \\
\hline Indonésia & obrigatória & produto & & $5 \%^{f}$ \\
\hline Rússia & obrigatória & produto & Todos os produtos baseados em conteúdo & $0,9 \%$ \\
\hline Arábia Saudita & obrigatória & produto & & $1 \%$ \\
\hline Coreia do Sul & $\begin{array}{l}\text { obrigatóriae } \\
\text { voluntáriah }\end{array}$ & produto & & $3 \%^{9}$ \\
\hline Taiwan & $\begin{array}{l}\text { obrigatóriae } \\
\text { voluntáriah }\end{array}$ & produto & & $5 \%$ \\
\hline Tailândiac & voluntária & produto & & $5 \%{ }^{f}$ \\
\hline Argentinad $^{d}$ & voluntária & produto & $\begin{array}{l}\text { Não especificado - Todos os produtos } \\
\text { baseados em conteúdo }\end{array}$ & - \\
\hline África do Sul & voluntária & produto & $\begin{array}{l}\text { Não especificado - Todos os produtos } \\
\text { baseados em conteúdo }\end{array}$ & - \\
\hline Filipinase & voluntária & produto & Todos os produtos baseados em conteúdo & $5 \%$ \\
\hline Canadá & voluntária & produto & Todos os produtos baseados em conteúdo & $5 \%$ \\
\hline Estados Unidos & voluntária & produto & Todos os produtos baseados em conteúdo & - \\
\hline
\end{tabular}

${ }^{\text {a }}$ somente para produtos substancialmente equivalentes; ${ }^{\text {b }}$ Regulamentação de rotulagem não foi totalmenteimplementada;

c Implementada com execução voluntária. São aplicadas penalidades em casos defraude; ${ }^{\circledR} \mathrm{N}$ ão há legislação específica;

${ }^{e}$ Regulamentação de rotulagem proposta; ${ }^{\dagger} \mathrm{N}$ os três principais ingredientes de cada produto; ${ }^{9} \mathrm{~N}$ os cinco ingredientes principais decada produto; ${ }^{\mathrm{h}}$ rotulagem voluntária para produtos não-GM .

Fonte: Gruèreet al. ${ }^{9}$.

disso. Porém, na Europa, os dois casos (doença da vaca louca e gripe do frango), puseram em questão a presença de organismos geneticamente modificados em alimentos, gerando uma for- te oposição por parte dos consumidores, além do aumento da procura por maiores informações sobre este tipo de produto. Este acontecimento acabou se traduzindo na demanda por 
rotulagem dos produtos alimentares que contenham OGM ${ }^{16}$.

Por estemotivo a União Europeia fixou o mais rigoroso regimedeimportações de OGM em todo o mundo. Os pedidos de aprovação de OGM para liberação no ambiente ou para colocação no mercado devem ser acompanhados por uma completa avaliação de risco identificando e avaliando os potenciais efeitos negativos do OGM, diretos ou indiretos, imediatos ou tardios, levando também em conta sua acumulação a longo prazo, efeitos sobre a saúde humana e o ambiente. Este procedimento foi reforçado no âmbito da revisão da Diretiva 2001/18/CE, relativa à liberação de OGM no ambiente, que entrou em vigor em 17 de outubro de 2002. Em particular, a Diretiva de 2001 introduz a obrigatoriedade de informar ao público, sobre notificações, avaliações e liberações de OGM, bem como normas gerais sobre rotulagem obrigatória e rastreabilidade em todas as etapas da colocação do mercado ${ }^{17}$.

Desde abril de 2004, os produtos alimentares que consistam de OGM s, ou que os contenham, ou que sejam obtidos a partir de OGMs, também estão sujeitos a exigências derastreabilidade e rotulagem, conforme estabelecido no Regulamento (CE) $1830 / 2003^{18}$.

A legislação da UE estabelece um limite em porcentagem para o conteúdo do material GM $(0,9 \%)$, acima do qual devem ser rotulados como alimentos que contenham ou sejam produzidos a partir de OGM . Abaixo desse nível, não precisam informar no rótulo, desde que o conteúdo GM seja de construções que tenham sido autorizadas na União Europeia para utilização eque se possa demonstrar que a presença é acidental e tecnicamenteinevitável ${ }^{10}$.

Para os novos alimentos e rações o regulamento prevê que deve haver um limite de $0,5 \%$ para a presença acidental desde que o material tenha passado por uma boa avaliação de risco e que o operador possa demonstrar que a sua presença é tecnicamente inevitável. Este limiar, porém só pode ser aplicada quando é possível testar a presença do material em questão. As diretivas 1829/03 e 1830/03 aumentam as atuais disposições relativas à rotulagem a todos os gêneros alimentícios e rações produzidos a partir de OGM , mesmo quesejam substancialmenteequivalentes aos derivados de fontes não-OGM e, portanto, nenhum DNA exógeno ou proteína podem ser detectados no produto final ${ }^{10}$.
Rotulagem de Produtos GM

nos Estados Unidos da América

Ao contrário de outras jurisdições, os Estados Unidos decidiram adaptar a legislação pré existente para incluir os produtos originados da biotecnologia. Ao fazêlo, estabel eceu um comitê global, o Escritório de Políticas de Ciência e Tecnologia ( $O$ ffice of Science and Technology Policy OSTP) para estudar e distribuir responsabilidades entreas diversas agências reguladoras: a FDA, a Environmental Protection Agency (EPA) e 0 United States Department of Agriculture(USDA) ${ }^{19}$.

0 resultado foi uma publicação descrevendo vários pontos importantes. 0 mais importante, a OSTP concluiu que o DNA recombinante não era inerentemente arriscado e que a regulamentação deverá concentrar-se sobre os riscos dos produtos, e não sobre os processos utilizados para desenvolvê-los; portanto, os produtos de DNA recombinantes não precisariam de nenhuma regulamentação nova ou especial. Em vez disso, a atual legislação e os regulamentos concebidos para os produtos atuais poderiam ser adaptados para lidar com produtos da biotecnologia. A estrutura coordenada também reconheceu 0 conceito de que os OGM não eram intrinsecamente mais arriscados do que os não-GM ${ }^{19}$.

O USDA, por intermédio do escritório deServiços Reguladores de Biotecnologia (BRS), do Animal and Plant Health Inspection Service (APHIS), está preocupado principalmentecom a proteção da agricultura e do ambiente de potenciais pragas. O USDA regulamenta todas as plantas obtidas por engenharia genética antes da liberação ambiental, incluindo a importação, as circulações interestaduais, os testes de campo e, naturalmente, o cultivo comercial (fazenda) ${ }^{19}$.

A FDA tem a responsabilidade de garantir a segurança dos alimentos humanos e 0 fornecimento de alimentos para animais. 0 Centro de Segurança Alimentar e Nutrição e do Centro de M edicina Veterinária avalia novos alimentos e rações GM , focando sua atenção na composição da alimentação humana e animal, procurando a presença de alérgenos e de toxinas novas ou alteradas, e analisando as alterações nos níveis de nutrientes presentes normalmente, fibras e outros constituintes habituais. A FDA tem provavelmentea maior experiência em lidar com OGM, começando com o primeiro produto comercializado GM , a insulina humana (1982) e, posteri- 
ormente, o primeiro produto alimentar, a quimosina, para fazer queijo, em 1990 (2 anos após, o mesmo produto foi aprovado para lançamento comercial no Reino Unido). A FDA também tratou da primeira aprovação de um produto alimentar, o tomate FlavrSavr ${ }^{\mathrm{TM}}$, em 1994.

A EPA éa autoridade responsável pelo desenvolvimento, comercialização, distribuição e avaliação depesticidas, com especial preocupação às ameaças à saúde humana e ao ambiente, e define os limites residuais desses pesticidas em culturas de plantas ${ }^{10}$.

Nos Estados Unidos, alimentos que contenham ingredientes GM disponíveis atualmente no mercado americano, não necessitam ser rotulados, uma vez que o FDA determinou que esses alimentos são "substancialmente equivalentes" aos seus homólogos não-GM. D esta forma, os consumidores americanos vêm se al imentando de produtos que contém ingredientes GM (fubá, óleos, açúcares) nos últimos 10 anos, enquanto permanecem al heios à presença de OGM nestes produtos ${ }^{20}$.

\section{Legislação para OGM no Brasil}

A Constituição Federal Brasileira de 1988²1, em seu artigo $225 \S 1$, dispõe que todos têm direito ao meio ambiente ecol ogicamente equilibrado, bem de uso comum do povo eessencial à sadia qualidadede vida, impondo-se ao Poder Público eà coletividade o dever de defendê lo e preservá-lo para as presentes e futuras gerações, e para assegurar a efetividade desse direito, incumbe ao Poder Público, através dos incisos:

II - preservar a diversidade e a integridade do patrimônio genético do País e fiscalizar as entidades dedicadas à pesquisa e manipulação de material genético;

IV - exigir, na forma da lei, para instalação de obra ou atividade potencialmente causadora de significativa degradação do meio ambiente, estudo prévio de impacto ambiental, a que se dará publicidade;

V - controlar a produção, a comercialização e o emprego de técnicas, métodos e substâncias que comportem risco para a vida, a qualidade de vida e o meio ambiente.

A Lei de Biossegurança n $n^{\circ} 11.105$ de 24 de março de $2005^{22}$ revoga a lei $n^{\circ} 8.974$ de 5 janeiro de $1995^{23}$ e estabelece normas de segurança e mecanismos de fiscalização sobre a construção, o cultivo, a produção, a manipulação, o transporte, a transferência, a importação, a exporta- ção, 0 armazenamento, a pesquisa, a comercialização, o consumo, a liberação no meio ambiente e o descarte de OGM e de seus derivados, tendo como diretrizes o estímulo ao avanço científico na área de biossegurança e biotecnologia, a proteção à vida e à saúde humana, animal e vegetal, e a observância do princípio da precaução para proteção do meio ambiente. Além disso, ela cria o Conselho Nacional de Biossegurança (CNBS), órgão de assessoramento superior do Presidente da República para formulação e implementação da Política Nacional de Biossegurança (PNB) ${ }^{22}$.

A liberação de OGM vem sendo condicionada à observância dessa Lei, que exige além do conhecimento cientifico acerca das características, riscos e propriedades de tais produtos, a observância de todo o procedimento previsto e avaliação prévia da Comissão Técnica N acional de Biossegurança, isto é, a realização do Estudo Prévio do Impacto Ambiental (EPIA) e apresentação de Relatório do I mpacto no M eio Ambiente(RIMA) visando desta maneira regulamentar o disposto no artigo 225 § 1ㅇ da Constituição Federal Brasileira. Com a ratificação pelo Brasil da Conven ção da Biodiversidade, a observância do princípio da precaução deve ser plena, pois não haveria outro caminho na ausência de segurança em relação ao meio ambiente senão ser cauteloso ${ }^{24}$.

A Resolução no 17 de 30 de abril de 1999 da Agencia Nacional de Vigilância Sanitária - ANVISA - estabeleceas diretrizes básicas para a avaliação do risco e segurança dos alimentos, para o controle sanitário dos alimentos, visando proteger a saúde da população 25 .

\section{A Comissão Técnica Nacional \\ de Biossegurança - CTNBio}

A CTN Bio, órgão criado pela M edida Provisória $n$ - 2.191-9 de 23 de agosto de 2001 e reestruturado pela nova Lei de Biossegurança, tem por função prestar apoio técnico consultivo e de assessoramento ao Governo Federal na formulação, atualização e implementação da Política $\mathrm{N}$ acional de Biossegurança (PNB), bem como estabelecer normas técnicas de segurança e de pareceres técnicos referentes à autorização para atividades que envolvam pesquisa e uso comercial de O GM eseus derivados, como basena avaliação de seu risco zoofitossanitário, à saúde humana e ao meio ambiente ${ }^{26}$.

O Decreto $\mathrm{n} 05.591$ de 22 de novembro de 2005 dispõe em seu artigo 4ํ, parágrafo único que: A CTN Bio deverá acompanhar o desenvolvimento e o progresso técnico e científico nas áreas 
de biossegurança, biotecnologia, bioética e afins, com o objetivo de aumentar sua capacitação para a proteção da saúde humana, dos animais e das plantas e do meio ambiente, além de dispor através de seus incisos sobre a composição eas competências da CTNBio, entre elas ${ }^{27}$ :

III - estabelecer, no âmbito de suas competências, critérios de avaliação e monitoramento de risco de OGM e seus derivados

IV - proceder à análise da avaliação de risco, caso a caso, relativamente a atividades e projetos que envolvam OGM e seus derivados;

VI - estabelecer requisitos relativos a biossegurança para autorização de funcionamento de laboratório, instituição ou empresa que desenvolverá atividades relacionadas a OGM e seus derivados;

VIII - autorizar, cadastrar e acompanhar as atividades de pesquisa com OGM e seus derivados, nos termos da legislação em vigor;

IX - autorizar a importação de OGM e seus derivados para atividade de pesquisa;

$X$ - prestar apoio técnico consultivo e de assessoramento ao Conselho Nacional de Biossegurança - CNBS na formulação da Política Nacional de Biossegurança de OGM e seus derivados;

XI - emitir Certificado de Qualidade em Biossegurança - CQB para o desenvolvimento de atividades com OGM e seus derivados em laboratório, instituição ou empresa e enviar cópia do processo aos órgãos de registro e fiscalização;

XII - emitir decisão técnica, caso a caso, sobre a biossegurança de OGM e seus derivados, no âmbito das atividades de pesquisa e de uso comercial de OGM e seus derivados, inclusive a classificação quanto ao grau de risco e nível de biossegurança exigido, bem como medidas de segurança exigidas e restrições ao uso;

XIV - classificar os OGM segundo a classe de risco, observados os critérios estabelecidos neste Decreto;

XVIII - apoiar tecnicamente os órgãos e entidades deregistro efiscalização, no exercício desuas atividades relacionadas a OGM e seus derivados;

\section{Aprovações comerciais no Brasil}

Em agosto de 2007, a CTNBio aprovou a liberação comercial do milho transgênico resistente a insetos da ordem Lepidóptera (milho Guardian, evento M ON810), desenvolvido pela empresa norte americana M onsanto. 0 transgênico é o segundo milho a ser liberado para comercialização pela CTN Bio desde a aprovação da nova lei de Biossegurança. Em maio, a comissão havia aprovado o Libert Link (T25), da empresa alemã Bayer e toleranteao herbicida glufosinato de amônio ${ }^{28-30}$.

No entanto, dois importantes órgãos de fiscalização ligados ao governo federal - a Anvisa e o Instituto Brasileiro do M eio Ambiente e dos Recursos N aturais Renováveis (I bama) - apresentaram recursos ao Consel ho $\mathrm{Nacional}$ de $\mathrm{Bi}$ ossegurança (CNBS) pedindo a anulação da decisão da CTNBio quanto a liberação do milho Liberty Link. Os recursos apresentados pelo I bama e pela Anvisa estão em acordo com a Lei de Biossegurança, a qual determina que as decisões da Comissão podem ser revogadas pelo CNBS, queé um colegiado composto por onze ministé rios (Casa Civil, Ciênciae Tecnologia, Saúde, M eio Ambiente, Desenvolvimento Agrário, Agricultura, Justiça, Desenvolvimento, Indústria eComércio Exterior, Relações Exteriores, D efesa e Secretaria Especial de Aquicultura e Pesca) ${ }^{31}$.

No documento ao CNBS, o Ibama evoca a possibilidade de que a deliberação tomada pela CTN Bio traga graves impactos para a saúde pública e, em especial, para o meio ambiente enumera as razões para isso: Inexistência de estudo prévio de impacto ambiental realizado nas condições edafoclimáticas do país; ausência de avaliação de risco, caso a caso, quefundamentea decisão da Comissão; ausência de Instrução N ormativa específica com diretrizes para analisar a avaliação derisco; ausência de plano e procedimentos de coexistência do cultivo de milho geneticamente modificado sem contaminação de outros tipos de milho e irregularidades processuais ${ }^{31}$. Em seu recurso, a Anvisa, ligada ao M inistério da Saúde, declara que o processo de liberação comercial do milho Liberty Link possui estudosinadequadoseinsuficientespara atestar a segurança alimentar e determinar os riscos à saúde pública da cultura geneticamente modificada. Entre as irregularidades apontadas pela agência estão a falta de estudos toxicológicos ou de alergenicidade. Na opinião da Anvisa, a Bayer deve apresentar estudos sobre as consequências do consumo do produto transgênico para a saúde humana e, em especial para a amamentação ${ }^{32}$.

A juíza federal Pepita Durski Tramontini M azini, da Vara Ambiental de Curitiba, havia determinado que a Comissão suspendesse novamente as deliberações sobre as liberações comerciais de milho transgênico. Segundo a decisão da juíza, as normas recém-elaboradas pela Comissão não atenderiam ao princípio da precaução eà Lei de Biossegurança e, portanto, deverão ser revistas. Com isso, as autorizações já concedidas para 
os milhos Liberty Link da Bayer e M ON 810 da M onsanto estariam suspensas ${ }^{32}$.

No entanto, em 12 de fevereiro de 2008, o CNBS, em reunião, julgou improcedentes os recursos interpostos pela Anvisa e pelo I bama, e ratificou o parecer técnico 987/2007, favorável à liberação comercial demilho geneticamentemodificado, evento T25 ou Liberty Link e o parecer técnico 1.100/2007, favorável à liberação comercial de milho geneticamente modificado, evento M ON 810 ou Milho Guardian 33,34.

Elaborar normas de coexistência e de monitoramento pós-liberação comercial de milhos transgênicos é requisito legal, e agora também judicial, para concretizar as autorizações já concedidas pela CTNBio e também para futuras autorizações. Por desobedecer a legislação, a CTN Bio foi obrigada, em julho desteano, por meio de decisão liminar, a estabelecer - previamentea qualquer liberação de milho transgênico - medidas de biossegurança para garantir a coexistência das variedades de milho orgânicas, convencionais ou agroecológicas com as variedades transgênicas. Também foi exigida a elaboração do plano de monitoramento aplicável após a introdução da espécie transgênica no meio ambiente ${ }^{32}$.

Atéo presentemomento, estão liberados para comercialização, além dos milhos Guardian (evento M ON 810) e Liberty Link (evento T25), os milhos Evento TC1507, GA21, Roundup Ready 2 (NK 60), evento BT 11, a soja Roundup Ready (evento GTS 40-3-2) e os al godões Bollgard (Bt) (evento 531), Widestrike (evento 281-24-236/ 3006-210-23) Roundup Ready (evento M ON 1445) e evento LLCotton25 $5^{35-37 .}$

Rotulagem de Produtos

que contém OGM no Brasil

A Lei no 8.078 de 11 desetembro de 1990, também conhecida como Código de Defesa do Consumidor (CDC), tem por objetivo 0 atendimento das necessidades do consumidor (toda pessoa física ou jurídica queadquire ou utiliza produto ou serviço como destinatário final), o respeito à sua dignidade, saúde e segurança, a proteção de seus interesses econômicos, a melhoria da sua qualidade de vida, bem como a transparência e harmonia das relações de consumo ${ }^{38}$.

Em seu artigo 60, o CDC dispõe os direitos básicos do consumidor, entre eles:

I - a proteção da vida, saúde esegurança contra os riscos provocados por práticas no fornecimento de produtos e serviços considerados perigosos ou nocivos;
III - a informação adequada e clara sobre os diferentes produtos eserviços, com especificação correta de quantidade, características, composição, qualidade e preço, bem como sobre os riscos que apresentem;

Em abril de 2003, o governo brasileiro emitiu o Decreto $\mathrm{n}-4.680^{39}$ regulamentando 0 direito à informação, assegurado pela Lei $n^{\circ} 8.078 / 90^{38}$, quanto aos alimentos e ingredientes alimentares destinados ao consumo humano ou animal que contenham ou sejam produzidos a partir de organismos geneticamente modificados.

0 artigo 20 deste decreto dispõe sobre a obrigatoriedade de rotulagem informando ao consumidor sobre a presença de organismo geneticamente modificado, caso sua presença seja detectada acima do limite estabelecido por lei ( $1 \%)$, tanto em produtos embalados quantos os vendidos a granel ou in natura, devendo constar em destaque no rótulo uma das seguintes expressões, dependendo do caso: (nome do produto) transgênico, contém (nome do ingrediente ou ingredientes) transgênico(s) ou produto produzido a partir de (nome do produto) transgênico, assim como o nome da espécie doadora do gene. Essas informações também deverão constar no documento fiscal, de modo que estes acompanhem 0 produto ou ingrediente em todas as etapas da cadeia produtiva39.

Os alimentos e ingredientes produzidos a partir de animais alimentados com ração contendo ingredientes transgênicos deverão trazer no painel principal, em tamanho edestaque previstos no art. $2^{\circ}$, a seguinte expressão: (nome do animal) alimentado com ração contendo ingrediente transgênico ou (nome do ingrediente) produzido a partir deanimal alimentado com ração contendo ingrediente transgênic0 ${ }^{39}$.

Aos alimentos eingredientes alimentares que não contenham nem sejam produzidos a partir de organismos geneticamente modificados será facultada a rotulagem (nome do produto ou ingrediente) livredetransgênicos, desdequetenham similares transgênicos no mercado brasileiro ${ }^{39}$.

Em complementação ao Decreto $\mathrm{n} 04.680 / 03$, a Portaria no 2.658 de 22 de dezembro de 2003 define a forma e as dimensões mínimas do símbolo que comporá a rotulagem tanto dos alimentos e ingredientes alimentares destinados ao consumo humano ou animal embalados como nos vendidos a granel ou in natura, que contenham ou sejam produzidos a partir de organismos geneticamente modificados ${ }^{40}$. A pesar da legislação de rotulagem para produtos transgênicos estar em vigor desde 2003, somente no início 
deste ano os primeiros produtos (óleo de soja) contendo OGM começaram a conter esta informação no rótulo.

Em 2007, a Anvisa abriu a consulta pública no 63 para definir padrões para procedimentos de avaliação desegurança destetipo dealimento pela Comissão Técnica Nacional da Política Nacional de Biossegurança relativa a OGM . A partir desta iniciativa da Anvisa, uma série de normas deverá ser cumprida na avaliação da segurança de alimentos que contenham OGM eseus derivados. A Consulta Pública 63 propôs 119 questões que visam avaliar se os dados apresentados pelos interessados em obter liberação comercial de produtos com OGM comprovam ou não a segurança de uso para o consumo humano. Essas questões estão divididas em quatro áreas de análise: modificação genética, organismos receptores, segurança al imentar equalidadenutricional. Os critériostécnicos previstos na consulta pública subsidiarão a atuação da Anvisa na Comissão de Biossegurança em Saúde (CBS) do M inistério da Saúde. A CBS, a pedido da CTNBio, avalia os processos relativos aos pedidos de liberação comercial de alimentos geneticamente modificados, incluindo os transgênicos. De acordo com a Lei de Biossegurança $n=11.105 / 05$, a liberação comercial de OGM ederivadosécompetência daCTN Bio, respeitadas as competências legais de fiscalização e regulamentação de outras instituições federais. Por isso, no caso dos transgênicos, o processo deliberação comercial passa por análise da CBS, da qual a Anvisa é membro permanente ${ }^{41}$.

A pesar de ser um assunto de al ta repercussão em todo o mundo, a informação aos consumidores, principais interessados no assunto, parece ser mínima. Uma pesquisa de opinião pública OPP573/2002 realizada pelo Instituto Brasileiro deO pinião Pública eEstatística (I bope) revela que os transgênicos não têm boa aceitação no Brasil. $65 \%$ dos pesquisados afirmam que os transgênicos deveriam ser proibidos. Além disso, 0 direito de não ingerir transgênicos deve ser garantido, acreditam os brasileiros. Uma outra informação é que a grande maioria, $92 \%$ dos entrevistados, diz que produtos com ingredientes transgênicos devem trazer esta informação no rótulo. A pesquisa também indica que a maioria da população brasileira nem sabe o que são transgênicos: $61 \%$ dos entrevistados nunca ouviram falar neles. Depois da explicação apresentada pelo entrevistador, $71 \%$ dos entrevistados disseram que se pudessem escolher entre um alimento modificado geneticamentee outro não modificado comeriam o quenão fosse transgênico. 0 estudo foi realizado a pedido do Instituto Brasileiro de Defesa do Consumidor (IDEC) ${ }^{42}$.

\section{Considerações finais}

Tendo em vista que a biotecnologia pode ofere cer, indubitavelmente, benefícios para o desenvolvimento sustentável, suprimento de alimentos e prosperidade econômica, com especial ênfase em países em desenvolvimento e, portanto, facilitando 0 alívio da pobreza, os países juntaram os seus esforços na elaboração de regras internacionais e regulamentações internas para garantir o desenvolvimento da biotecnologia para o benefício da sociedade em geral e a conservação dos recursos genéticos, especialmente nos centros de origem (na sua maioria situados no terceiro mundo) ${ }^{10}$.

Existem vários modelos de tais regulamentações nacionais que podem ser eficazes na criação de um sistema operacional debiossegurança. Qual o modelo a ser escolhido depende da política de determinado país e deve estar em conformidade com as suas obrigações internacionais e regionais. Sabe-se quea harmonização internacional e regional, juntamente com a sincronização dos quadros regulatórios nacionais, deverão centrarse sobre as questões do reforço de capacidades e no compartilhamento de informações para se obter segurança biotecnológica. Muitos países, especialmente os em desenvolvimento, precisam adquirir a tecnologia e capacidades necessárias para lidar sustentavel mente com os resultados da biotecnologia moderna. Por isso, a consciência pública, a educação e a transferência de tecnologia desempenham um papel importante ${ }^{10}$.

No Brasil, a legislação específica existe e está em vigor, e, no entanto, não há controle algum sobre a aplicação desta sobre os produtos comercializados aqui. A defasagem entre 0 estabelecimento da lei (2003) e os primeiros produtos rotulados no mercado (2008) é de cinco anos.

Um outro problema que pareceser ainda mais crítico éa falta de informação da população brasileira que pouco sabe sobre os transgênicos, e, desconhecea existência de uma legislação que dá a oportunidade de escolha sobre a aquisição de produtos que contenham ou não O GM , fazendo com que esta perca sua força e até mesmo sua finalidade. 


\section{Colaboradores}

TEM M C C osta atuou na concepção, delineamento, análise e interpretação dos dados, redação e revisão crítica do artigo.VA M arin atuou na análise einterpretação dos dados e revisão crítica do artigo.

\section{Referências}

1. Cardarelli P, Branquinho M R, Ferreira RTB, Cruz $F P, G e m a l$ AL. Detection of GMO in food products in Brazil: the INCQS experience. Food Control 2005; 16(10):859-866.

2. James C. Situação Global da Comercialização das Lavouras GM : 2006. Sumário Executivo 35 International Service for the Acquisition of Agro-Biotech Applications (ISAAA). 2006. [acessado 2007 abr 27]. Disponível em: http://www.isaaa.org/resources/ publications/briefs/35/executivesummary/pdf/ Brief $\% 2035 \% 20$ - $\% 20$ Executive $\% 20$ Su mmary $\% 20$ $\% 20$ Portuguese.pdf.

3. Brookes G, Barfoot P. GM crops: the first ten years - global socio-economic and environmental impacts. ISAAA Brief 2006; 36.

4. Mazza R, Soave M, M orlacchini M, Piva G, Marocco $A$. Assessing the transfer of genetically modified DNA from feed to animal tissues. Transgenic Research 2005; 14(5):775-784.

5. Nodari RO, Guerra M P. Avaliação de riscos ambientais de plantas transgênicas. Cadernos de Ciência e Tecnologia 2001; 18(1):81-116.

6. Kulikov AM. Genetically modified organisms and risk of their introduction. Russian Journal of Plant Physiology 2005; 52(1):99-111.

7. Esposito V, Kolodinsky J. Consumer Attitudes and Policy Directions for GM Labeling and Pollen Drift Regulation: Evidence from the 2006 Vermonter Poll. AgBio Forum 2007; 10(2):85-93.

8. Organization for Economic Cooperation and Development (OECD). Biotechnology regulatory developments in OECD member countries. Paris, 2003. [acessado 2007 fev 17]. Disponível em : http://www. oecd.org/oecd/pages/home/displaygeneral/0,3380, EN-document-531-14-no-no-9598-0,00.html

9. Gruère GP, Rao SR A review of international labeling policies of genetically modified food to evaluate India's proposed rule. AgBio Forum 2007; 10(1): 51-64.

10. Alexandrova N, Georgieva K, Atanassov A. Biosafety regulations of gmos: national and international aspects and regional cooperation. Biotechnolology \& Biotechnological Equipment 2005; 19:153-172.

11. Convenção sobre Diversidade Biológica. Protocolo de Cartagena sobre biossegurança. [acessado 2007 out 28]. Disponível em: http://www.cdb.gov.br/cartagena.

12. Convention on Biological Diversity. [acessado 2008 jan 15]. Disponível em: http://www.cbd.int/meetings/ cop8mop3/mop-03.shtml/.
13. Carter CA, Gruere GP. International Approaches to the Labeling of Genetically M odified Foods. Agricultural M arketing Resource Center 2003; Mar:1-6.

14. Carter CA. International approaches to the labeling of genetically modified foods. Agricultural and Resource Economics U pdate 2002; 6(1):1-6.

15. Silva V, Amaral AM P. Segurança alimentar, comércio internacional e segurança sanitária. Informações Econômicas 2004; 34(6):38-45.

16. Scandizzo S. International trade and the labelling of Genetically M odified Organisms. Briefing N otes in Economics 2002; 54. [acessado 2007 set 22]. Disponível em: http://www.richmond.ac.uk/bne.

17. Baumuller $\mathrm{H}$. Domestic Import Regulations for Genetically Modified Organisms and their Compatibility with WTO Rules. Trade Knowledge Network 2003.

18. Moschini GC, Lapan $\mathrm{H}$. Labeling regulations and segregation of first- and second-generation genetically modified products: innovation incentives and welfare effects. Apr. 2005. [acessado $2007 \mathrm{dez}$ 06] Disponível em: http://www.card.iastate.edu/faculty/ profiles/giancarlo_moschini/moschini-lapanchapter-just-ook.pdf.

19. $\mathrm{MCH}$ ughen $\mathrm{A}$, Smyth S. US regulatory system for genetically modified [genetically modified organism (GMO), rDNA or transgenic] crop cultivars. Plant Biotechnology Journal 2007; 6(1):2-12.

20. Fernandez-Cornejo J, Caswell M. The first decade of genetically engineered crops in the U nited States. Economic Research Service 2006; 11. [acessado 2007 set 23]. Disponível em: http://www.ers.usda.gov/ Publications/EIB11/.

21. Brasil. Constituição (1988). Constituição [da] República Federativa do Brasil. [acessado 2007 dez 15]. Disponível em: http://www.planalto.gov.br/ccivil_03/ Constituicao/Constitui\%C3\%A7ao.htm.

22. Brasil. Lei $n^{\circ} 11.105$, de 24 de $M$ arço de 2005. Regulamenta os incisos II, IV e V do $\S 10$ do art. 225 da Constituição Federal, estabelece normas de segurança e mecanismos de fiscalização de atividades que envolvam organismos geneticamente modificados - OGM e seus derivados, cria o Conselho Nacional de Biossegurança - CNBS, reestrutura a Comissão Técnica Nacional de Biossegurança CTNBio, dispõe sobre a Política Nacional de Biossegurança - PNB, revoga a Lei no 8.974, de 5 de Janeiro de 1995, e a M edida Provisória no 2.191-9, de 23 de Agosto de 2001, e os arts. 50, 60, 7ㅇ, 8ㅇ, 9으, 10 e 16 da Lei $n=10.814$, de 15 de Dezembro de 2003, e dá outras providências. [acessado 2006 out 28]. Disponível em: http://www.mct.gov.br/index. $\mathrm{php/content/view/1034.html.}$ 
23. Brasil. Lei no 8.974, de 05 de janeiro de 1995. Regulamenta os incisos II e V do $\S 10$ do art. 225 da Constituição Federal, estabelece normas para o uso das técnicas de engenharia genética e liberação no meio ambiente de organismos geneticamente modificados, autoriza o Poder Executivo a criar, no âmbito da Presidência da República, a Comissão Técnica Nacional de Biossegurança, e dá outras providências. Diário Oficial [da] República Federativa do Brasil 1995; 06 jan. [acessado 2006 out 28]. Disponível em: http://www.mct.gov.br/index.php/content/view/1043. html

24. Anez TLW. Organismos geneticamente modificados: uma abordagem à luz do direito nacional e internacional. Revista da Faculdade de Direito da U niversidade Federal do Paraná 2005; 43:1-12.

25. Brasil. ANVISA. Resolução no 17, de 30 de abril de 1999. Aprova o Regulamento Técnico que estabelece as Diretrizes Básicas para a Avaliação de Risco e Segurança dos Alimentos. Diário Oficial [da] Re pública Federativa do Brasil 1999; 03 maio.

26. Brasil. M edida Provisória n 2.191-9, de 23 de agosto de 2001. Acresce e altera dispositivos da Lei no 8.974 , de 5 de janeiro de 1995, e dá outras providências. [acessado 2006 out 28]. Disponível em: http://www. planalto.gov.br/CCIVIL/M PV/21919.htm

27. Brasil. Decreto no 5.591, de 22 de novembro de 2005. Regulamenta dispositivos da Lei $n^{\circ} 11.105$, de 24 de março de 2005, que regulamenta os incisos II, IV e V do $\S 1^{\circ}$ do art. 225 da Constituição, e dá outras providências. [acessado 2007 dez 15]. Disponível em: http://www.planalto.gov.br/CCIVIL/ Ato2004-2006/2005/Decreto/D5591.htm

28. Brasil. Comissão Técnica Nacional de Biossegurança. Extrato de parecer técnico № 1.099/2007. Diário Oficial da União 2007; 4 set.

29. Brasil. Comissão Técnica Nacional de Biossegurança. Extrato de parecer técnico № 1.100/2007. Diário Oficial da União 2007; 4 set.

30. Mattedi JC. CTNBio aprova nova liberação de miIho transgênico para venda no país. Agência Brasil. out. 2007. [acessado 2008 jan 15]. Disponível em: http://www.agenciabrasil.gov.br/noticias/2007/08/ 16/materia.2007-08-16.6769 437960/ view>

31. Thuswohl M. Ibama e Anvisa pedem anulação da liberação de milho transgênico. IDEC. Jul. 2007. [acessado 2008 jan 17]. Disponível em: http:// www.idec.org.br/noticia.asp?id=8426

32. Greepeace. Ibama e Anvisa contestam CTNBio e pedem anulação da liberação de milho transgênico. Jul., 2007. [acessado 2008 jan 17]. Disponível em: http://www.greenpeace.org/brasil/transgenicos/ noticias/ibama-e-Anvisa-contestam-ctnbi

33. Brasil. Comissão Técnica Nacional de Biossegurança. Resolução CNBS No 2, de 5 de março de 2008. Ratifica o Parecer Técnico no 987/2007 da Comissão Técnica Nacional de Biossegurança CTNBio, favorável à liberação comercial de milho geneticamente modificado, evento T25 ou Liberty Link. [acessado 2008 maio 9]. Disponível em: http:/ /www.ctnbio.gov.br/index.php/content/view/ 11446.html
34. Brasil. Comissão Técnica Nacional de Biossegurança. Resolução CNBS № 3, de 5 de março de 2008. Ratifica o Parecer Técnico no 1.100/2007 da Comissão Técnica Nacional de Biossegurança - CTNBio, favorável à liberação comercial de milho geneticamente modificado, evento MON810 ou Milho Guardian. [acessado 2008 maio 9]. Disponível em: http:/ /www.ctnbio.gov.br/index.php/content/view/11445. html

35. Brasil. Comissão Técnica Nacional de Biossegurança. Technical conclusive opinion. Set. 1998. [acessado 2007 mai 1]. Disponível em: http:// www.ctnbio.gov.br/index.php/content/view/3664. html

36. Brasil. Comissão Técnica Nacional de Biossegurança. Previous conclusive technical opinion. Mar. 2005. [acessado 2007 mai 1]. Disponível em: http:/ /www.ctnbio.gov.br/index.php/content/view/3663. html

37. Brasil. Comissão Técnica Nacional de Biossegurança. A provações Comercias / Plantas. [acessado 2009 mar 25]. Disponível em: http://www.ctnbio.gov.br/ index.php/content/view/12482.html

38. Brasil. Lei $n^{0} 8.078$, de 11 de setembro de 1990. Dispõe sobre a proteção do consumidor e dá outras providências. [acessado 2007 mai 1]. Disponível em: http://www.planalto.gov.br/ccivil/leis/L8078.htm

39. Brasil. Decreto no 4680 de 24 de abril de 2003. Regulamenta 0 direito à informação, assegurado pela Lei no 8.078, de 11 de setembro de 1990, quanto aos alimentos e ingredientes alimentares destinados ao consumo humano ou animal que contenham ou sejam produzidos a partir de organismos geneticamente modificados, sem prejuízo do cumprimento das demais normas aplicáveis. [acessado 2007 mai 1]. Disponível em: http://www.agricultura.gov.br/ portal/page?_pageid $=33,964715 \&$ _dad $=$ portal $\&$ _ schema=PORTAL

40. Brasil. Portaria $n^{\circ} 2658$, de 22 de dezembro de 2003. Define 0 símbolo de que trata 0 art. $2^{\circ} \stackrel{0}{\S} 1_{1}$, do Decreto 4.680, de 24 de abril de 2003. [acessado 2007 jun 04]. Disponível em: http://www.agricultura. gov.br/portal/page?_pageid $=33,964543 \&$ _dad $=$ portal\&_schema=PORTAL

41. Agência $\mathrm{N}$ acional de Vigilância Sanitária. Alimento geneticamente modificado: critérios garantirão mais segurança. N otícias da ANVISA, jul. 2007; [acessado 2008 jan 10]. Disponível em: http://www.Anvisa. gov.br/divulga/noticias/2007/240707.htm

42. Instituto Brasileiro de Opinião Pública e Estatística. Produtos com ingredientes transgênicos devem trazer a informação no rótulo. jan 2003. [acessado 2008 jan 10]. Disponível em: http://www.ibope.com.br/ calandraWeb/servlet/CalandraRedirect?temp $=6 \&$ proj=Portall BO PE $\&$ pub $=T \& d b=c a l d b \& \operatorname{comp}=$ pesquisa_leitura\&nivel=null $\&$ docid=FEBCFCAC 4834A A 0283256EA20065E 173

Artigo apresentado em 12/05/2008

A provado em 27/03/2009

Versão final apresentada em 12/04/2009 